\title{
Análise da presença da atividade da enzima alfa-amilase salivar na espécie bovina
}

\author{
Natan Dias de Oliveira ${ }^{1 *}$; Anne Karoline Mendes da Silva²; Valéria Magro Octaviano Bernis ${ }^{3}$; Walter Octaviano \\ Bernis Filho ${ }^{4}$
}

DOI: https://doi.org/10.35699/2447-6218.2021.26074

\begin{abstract}
Resumo
A principal enzima salivar responsável pela digestão dos carboidratos é a alfa-amilase. Entretanto, estudos sobre a presença desta enzima em bovinos são escassos e as vezes contraditórios. Diante disso, o objetivo dessa pesquisa foi verificar a presença da atividade da enzima alfa-amilase em bovinos. O método usado para a determinação da enzima foi o colorimétrico modificado, utilizando para tal o kit comercial "Amilase Colorimétrica K003" ( Bioclin, Quibasa Química Básica Ltda, Belo Horizonte, MG, Brasil). A análise foi realizada mediante a visualização macroscópica da coloração após a amostra ser incubada com o substrato amido, e pela adição do iodo; o amido não hidrolisado adquire coloração azul/preta que diminui proporcionalmente à atividade enzimática, sendo comparado com um controle. Observou-se que nenhuma amostra apresentou resultados colorimétricos que apontam a presença da alfa amilase, sendo assim possível sugerir que, não há presença significativa desta proteína na saliva de bovinos que seja capaz de hidrolisar o amido.
\end{abstract}

Palavras-chave: Amido. Bovino. Enzima digestiva. Glândula salivar.

\section{Analysis of the presence of the activity of the salivary alpha-amylase enzyme in bovine species}

\begin{abstract}
The main salivary enzyme responsible for carbohydrate digestion is alpha-amylase. However, researches on the presence of this enzyme in bovine species are minimal and contradictory. Accordingly, the aim of this investigation was to analyze the presence of alpha-amylase enzyme activity in the saliva in bovine species. The protocol used to determine the enzyme was the modified colorimetric kit "Amilase Colorimétrica K003" (Bioclin, Quibasa Química Básica Ltda, Belo Horizonte, MG, Brazil). The analysis was performed through macroscopic visualization of the staining after the sample was incubated with the starch substrate, and when adding iodine, not hydrolyzed starch acquires blue/black coloration that decreases proportionally to the enzymatic activity, being compared with a control. It was observed that no sample presented colorimetric results that indicate the presence of the alpha amylase, being possible to conclude that, there is no significant presence of these protein in the saliva of bovine species that be able to hydrolize the starch.
\end{abstract}

Keywords: Starch. Enzymatic activity. Bovine. Salivary gland.

\footnotetext{
${ }^{1}$ Instituto Federal do Norte de Minas Gerais. Salinas, MG. Brasil. https://orcid.org/0000-0001-5446-6744

${ }^{2}$ Instituto Federal do Norte de Minas Gerais. Salinas, MG. Brasil. https://orcid.org/0000-0002-9494-1500

${ }^{3}$ Instituto Federal do Norte de Minas Gerais. Salinas, MG. Brasil. https://orcid.org/0000-0001-8248-160X

${ }^{4}$ Instituto Federal do Norte de Minas Gerais. Salinas, MG. Brasil. https://orcid.org/0000-0001-6553-6808

*Autor para correspondência: ndias404@gmail.com
}

Recebido para publicação em 31 de outubro de 2020. Aceito para publicação em 10 de março de 2021 e-ISSN: 2447-6218 / ISSN: 2447-6218. Atribuição CC BY. 


\section{Introdução}

O homem e os ruminantes têm dividido uma longa história de produção desde o início dos tempos, inicialmente de uma forma nômade, e agora com modernas formas de manejo, principalmente no aspecto nutricional. Assim, com a constante evolução da nutrição nesta espécie, o interesse sobre a digestão de bovinos tem aumentado amplamente (Berchielli; Pires; Oliveira, 2011).

A nutrição de ruminantes, em sua maioria, está baseada nas pastagens tropicais, contudo, visto o inadequado manejo do pasto e a sazonalidade nos períodos de seca, torna-se necessário buscar alternativas para suprir as exigências dos animais e, consequentemente, obter um produto final de qualidade. $\mathrm{O}$ uso de concentrados, seja ele com suplemento ou no próprio confinamento, são opções para atender essas exigências, porém, a necessidade de aumentar a densidade energética das dietas maximiza o uso desses concentrados, podendo acarretar distúrbios metabólicos (Alves, et al., 2003).

Os problemas digestivos são frequentes em bovinos e, na sua maioria, estão relacionados a um inadequado manejo nutricional, seja pelo fornecimento de nutrientes em excesso como já dito, principalmente em sistemas intensivos de criação, ou devido ao fornecimento de alimentos em quantidade ou qualidade inadequada, situação mais observada em sistemas extensivos de criação em condições de escassez de forragens (Lima, et al. 2008, Gheller, et al. 2010, Burns, et al. 2013).

A maior parte dos componentes das dietas, incluindo os carboidratos, são demasiadamente grandes para sofrerem absorção direta através do epitélio intestinal e no sangue. Dessa forma, é necessário que ocorra o processo de digestão, que é onde ocorre a decomposição do alimento em pequenos fragmentos (Reece, 2017).

Essa redução física da partícula é importante não apenas para permitir que o alimento flua por um tubo digestivo relativamente estreito, mas também para aumentar a área de superfície das partículas de alimento, facilitando o contato das enzimas digestivas que agem clivando moléculas maiores em moléculas menores capazes de serem absorvidas (Klein, 2014).

Dentre as enzimas estudadas no processo digestivo, podemos citar a alfa-amilase salivar e a alfa-amilase pancreática, que possuem importante participação na digestão de carboidratos. Durante a digestão, os amidos da dieta começam a ser clivados na boca pela alfa-amilase salivar (Reece, 2017). Essa enzima tem como função biológica dividir o amido em maltose, maltotriose e dextrinas entretanto, estudos sobre a presença de amilase salivar em animais são escassos e contraditórios entre literaturas (Almeida, et al., 2008)

Alguns estudos afirmam a ausência da enzima alfa- amilase salivar em bovinos adultos ou bezerros (Young e Schneyer, 1981; Lima, et al., 2013), porém, outros autores demonstraram a atividade da enzima alfa-amilase salivar na mesma espécie (Reece, 2017; Alves, Costa e Moraes, 2016). Nesse contexto, o objetivo desse trabalho foi analisar a presença ou ausência da atividade da enzima alfa-amilase na saliva de bovinos e que este trabalho possa contribuir para estudos futuros sobre digestão dos ruminantes.

\section{Material e métodos}

\section{Coleta de amostras}

Para este estudo foram analisadas amostras de saliva oriundas de animais da Unidade Educativa de Produção de Zootecnia III do Instituto Federal do Norte de Minas Gerais (IFNMG) - Campus Salinas, localizado na Fazenda Varginha, Rodovia MG-404, Km 02, Salinas-MG. O protocolo experimental desse trabalho foi aprovado pela Comissão de Ética na Utilização dos Animais (CEUA) do Instituto Federal do Norte de Minas Gerais sob o protocolo de número 06/2020.

Foram coletadas treze amostras, onde oito bovinos, fêmeas adultas e em lactação estavam alimentadas com dieta balanceada, e as outras cinco amostras de bezerros lactentes. A dieta balanceada era constituída por $55 \%$ de milho, $38 \%$ de farelo de soja, $2 \%$ de ureia, $3,5 \%$ de suplemento mineral, $1 \%$ de óleo mineral e $0,5 \%$ de bicarbonato de sódio.

A coleta da saliva foi realizada após a ordenha, tanto de adultas como lactantes devido a facilidade de contenção e manejo dos animais. Com o auxílio de luvas e swab do tipo zaragatoa, as amostras foram coletadas do vestíbulo oral dos animais através de um esfregaço (todas em um mesmo dia, no período da tarde) (Figura 1). Durante a coleta, foram preenchidas fichas que continham as identificações por brinco, sexo e tipo de alimentação (Tabela 1).

O swab foi inserido em microtubo tipo eppendorf (tubo de microcentrífuga - Figura 2) para a deposição da saliva. Os microtubos se encontravam identificados e com $2 \mathrm{~mL}$ de solução fisiológica estéril ( $\mathrm{NaCl}$ 0,9\%). Posteriormente, o material coletado foi acondicionado em caixa de isopor com gelo (Figura 2), para serem conduzidas ao laboratório e armazenadas em freezer de geladeira e mantidas congeladas a $-10^{\circ} \mathrm{C}$, para posterior determinação da presença da atividade da enzima alfa-amilase salivar. 
Análise da presença da atividade da enzima alfa-amilase salivar na espécie bovina

Figura 1 - Coleta de saliva através de esfregaço com swab no vestíbulo oral. (Fonte: arquivo da pesquisa)

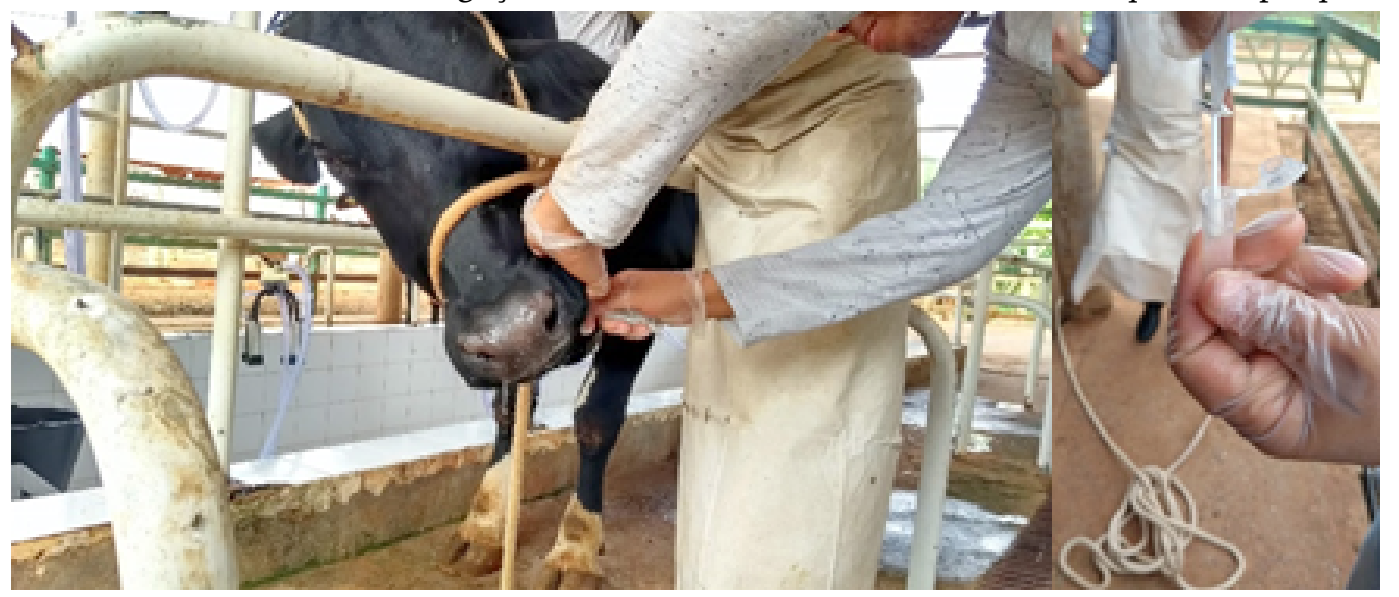

Figura 2 - Microtubos tipo eppendorf identificados e com 2,0 $\mathrm{mL}$ de solução de $\mathrm{NaCl} \mathrm{0,9 \% .} \mathrm{(Fonte:} \mathrm{arquivo} \mathrm{da} \mathrm{pesquisa)}$

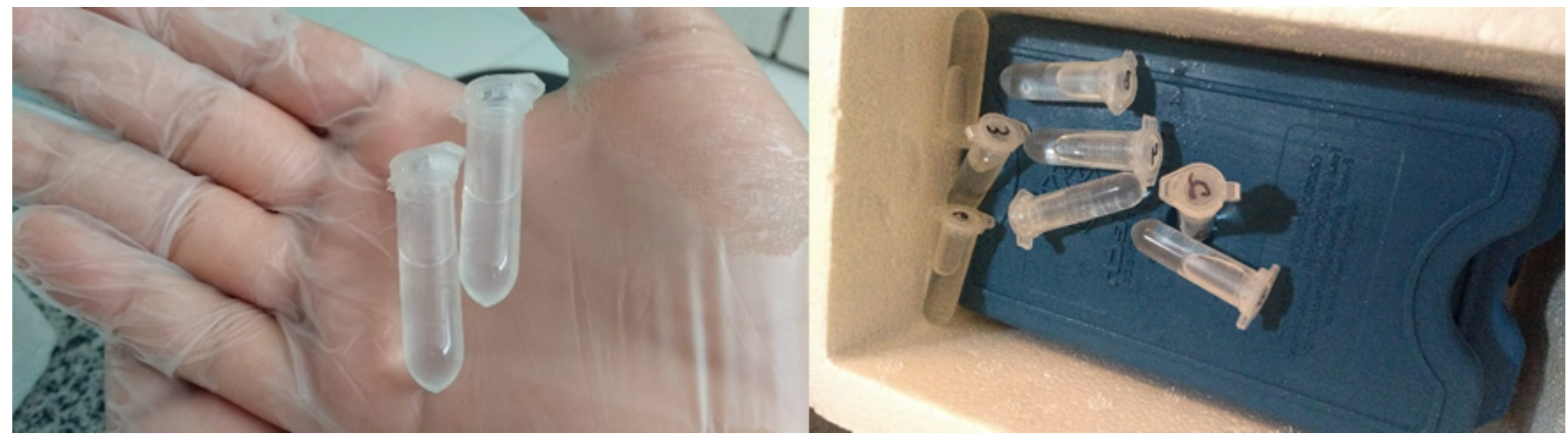

Tabela 1 - Identificação dos animais que foram coletadas as amostras. (Fonte: dados da pesquisa)

\begin{tabular}{lccc}
\hline Bovino/amostra & Identificação do brinco & Sexo & Alimentação \\
\hline B01 & $8509-12$ & Fêmea & Dieta balanceada \\
B02 & 7801 & Fêmea & Dieta balanceada \\
B03 & 061 & Fêmea & Dieta balanceada \\
B04 & $8802-13$ & Fêmea & Dieta balanceada \\
B05 & 081 & Fêmea & Dieta balanceada \\
B06 & 085 & Fêmea & Dieta balanceada \\
B07 & $0210-10$ & Fêmea & Dieta balanceada \\
B08 & 080 & Fêmea & Dieta balanceada \\
B09 & $6009-19$ & Macho & Lactente \\
b10 & $8806-19$ & Fêmea & Lactente \\
b11 & $7809-19$ & Macho & Lactente \\
b12 & $8107-19$ & Fêmea & Lactente \\
b13 & $0210-19$ & Fêmea & Lactente \\
\hline
\end{tabular}

Em que: B: Vacas em Lactação; b: Bezerros lactentes

\section{Análise laboratorial}

As análises foram feitas 24 horas após a coleta, sendo conduzidas em laboratório do Complexo de
Atendimento Clínico Veterinário do mesmo campus. Os microtubos tipo eppendorf foram retirados do freezer e deixados para descongelar em temperatura ambiente. 
Oliveira, N. D. et al.

Após o descongelamento, os tubos foram homogeneizados para a realização das análises.

O protocolo usado foi o descrito no kit colorimétrico específico (Amilase Colorimétrica K003, Bioclin, Quibasa Química Básica Ltda, Belo Horizonte, MG, Brasil) e adaptado, sendo utilizado como base o método colorimétrico modificado (Caraway, 1959), onde a amostra de saliva é incubada com o substrato amido (Reagente no 1) e aquecida em temperatura de $38,6^{\circ} \mathrm{C}$, durante dois minutos, para simular a temperatura média do corpo de um bovino. Pela adição da solução iodada (Reagente no 2), o amido ainda não hidrolisado, adquire coloração azul que diminui proporcionalmente à atividade enzimática, sendo comparado com um controle.

Figura 3 - Kit de reagentes para determinação colorimétrica da amilase. (Fonte: arquivo da pesquisa).

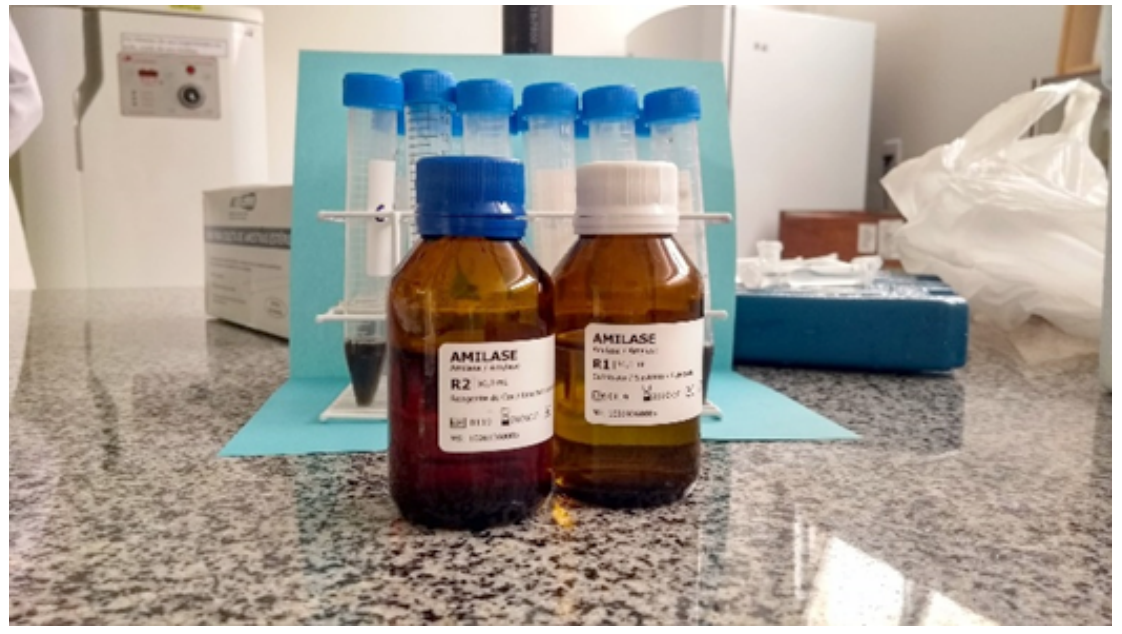

Para o controle foi utilizada uma amostra de saliva humana. A saliva humana possui constante atividade da enzima digestiva alfa-amilase ( Hall, 2011). Foi realizado um teste inicial com saliva humana, seguindo detalhadamente o método inicial, validando a técnica empregada com o aspecto de saliva reagente.
Os tubos tipo Falcon foram separados e identificados (Figura 4). Os tubos marcados com "B", referem-se às vacas lactantes, e "b", referem-se aos bezerros lactentes. Também foi adicionado um tubo controle. Com base nas instruções do kit colorimétrico, foram distribuídos 0,5 $\mathrm{mL}$ do reagente $\mathrm{n} \mathrm{o} 1$ em cada tubo, que foram mantidos por dois minutos em banho-maria à $38,6^{\circ} \mathrm{C}$.

Figura 4 - Tubos tipo Falcon devidamente identificados (Fonte: arquivo da pesquisa).

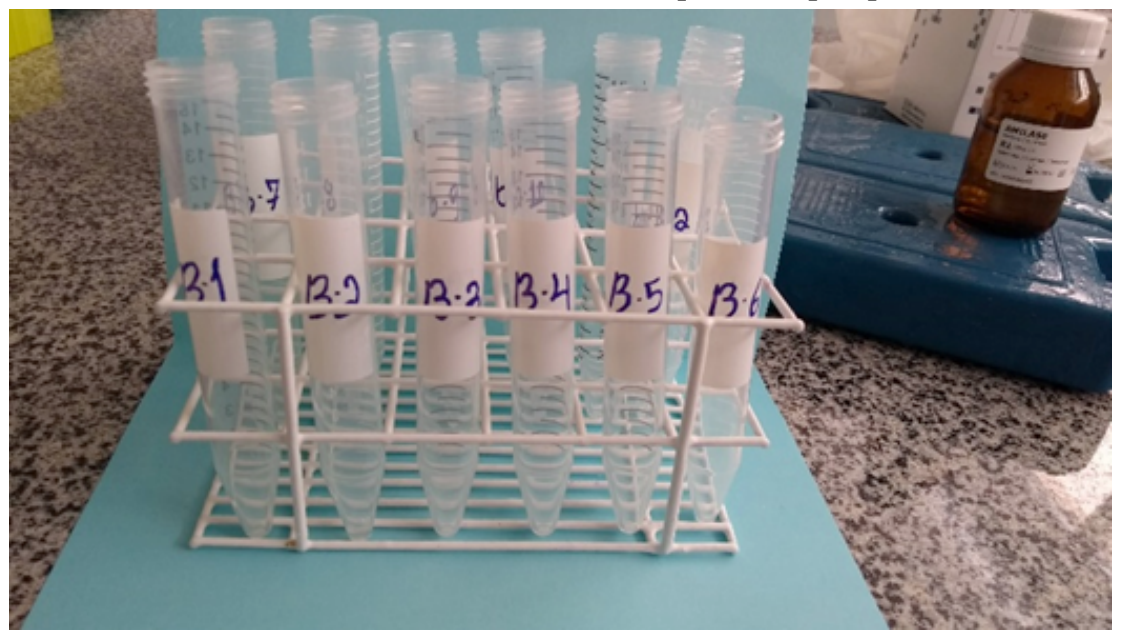

Ao serem retirados do banho-maria, foram adicionados $10 \mu \mathrm{L}$ de cada amostra de saliva em cada tubo. $\mathrm{O}$ controle não obteve nenhuma adição. Em seguida foram homogeneizados e mantidos em banho-maria por sete minutos e trinta segundos à $38,6^{\circ} \mathrm{C}$. Após a retirada o tubo foi adicionado $0,5 \mathrm{~mL}$ do reagente $\mathrm{n}$ o 2 , e homogeneizou-se. A análise da presença da atividade da enzima alfa-amilase salivar foi feita mediante a visualização macroscópica da coloração da amostra obtida.

\section{Resultados e discussão}

Dos treze animais analisados oito eram animais adultos e cinco eram filhotes, que possuíam fases de desenvolvimento e alimentação distintas. Observou-se que 
nenhuma amostra apresentou resultados colorimétricos significativos da presença da atividade da enzima alfa-amilase salivar, possuindo a mesma coloração do teste controle (Figura 6). Por meio da Figura 7, é evidente a eficácia da metodologia pela análise que foi realizada com amostra salivar humana, reconhecidamente descrita com a presença desta enzima (Hall, 2011). O amido foi hidrolisado e deixou a amostra com coloração amarelada.

Figura 5 - Tubos com reagente № 1 sendo preparados e alocados em banho-maria. (Fonte: arquivo da pesquisa)

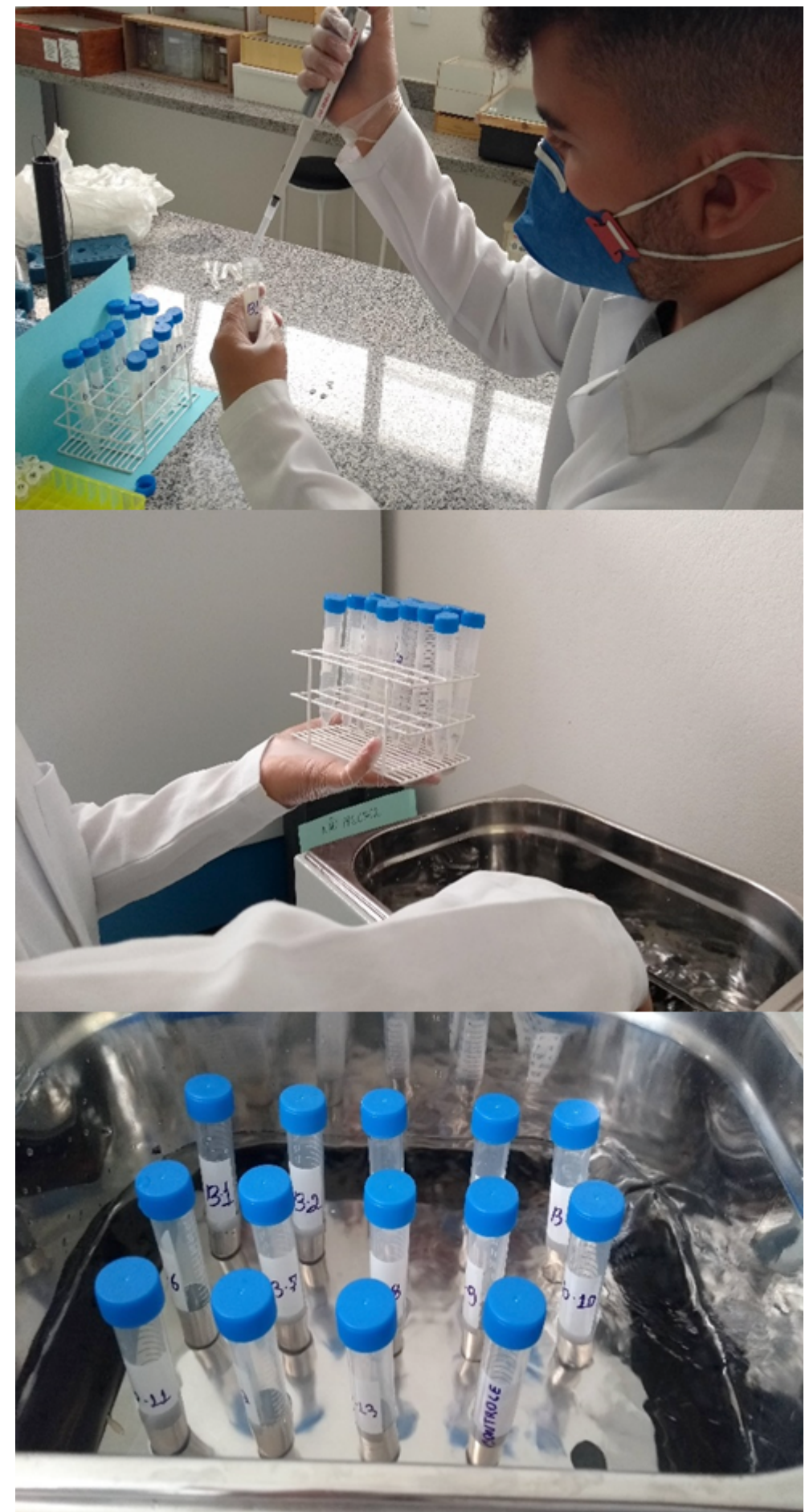

Os resultados obtidos corroboram com estudos de Young e Schneyer (1981) e Andriguetto-Filho (2002) que apontaram a ausência da atividade da enzima alfa-amilase salivar em bovinos adultos. Nos estudos de Lima, et al. (2013), citam a ausência de amilase salivar em bezerros.

\section{Conclusão}

Com os resultados desse trabalho podemos concluir que, ao realizar a análise laboratorial dessas amostras coletadas, observa-se que não há presença significativa da alfa-amilase na saliva de bovinos adultos ou jovens que seja capaz de hidrolisar o amido. 
Oliveira, N. D. et al.

Figura 6 - Amostra com resultado negativo para a atividade da enzima. (Fonte: arquivo da pesquisa)

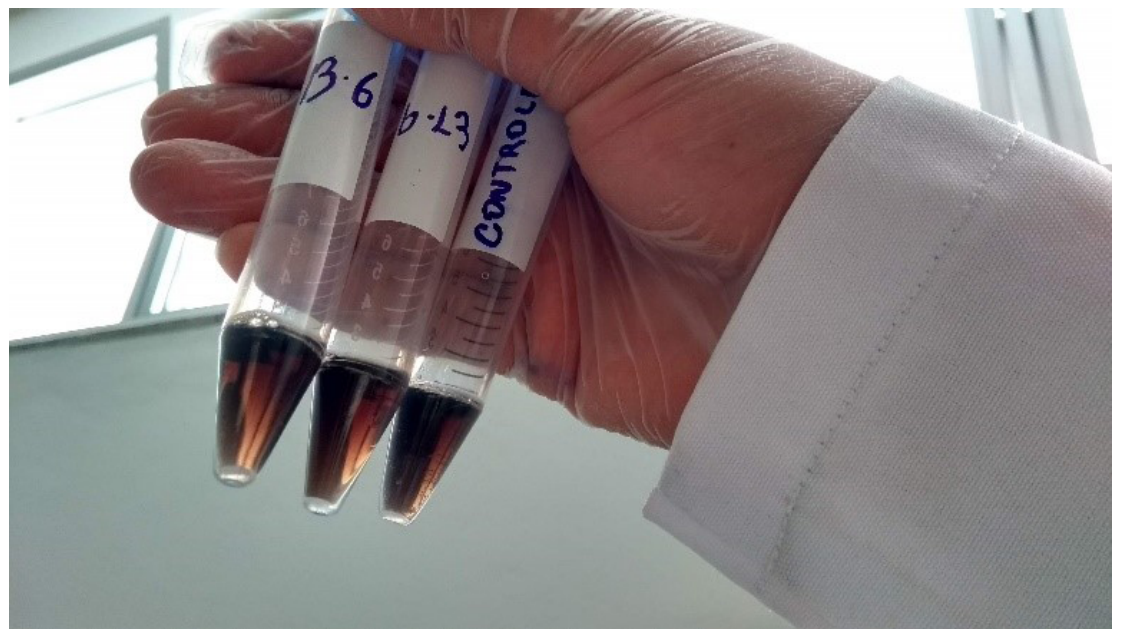

Figura 7 - Amostra de saliva humana hidrolisada. (Fonte: arquivo da pesquisa)

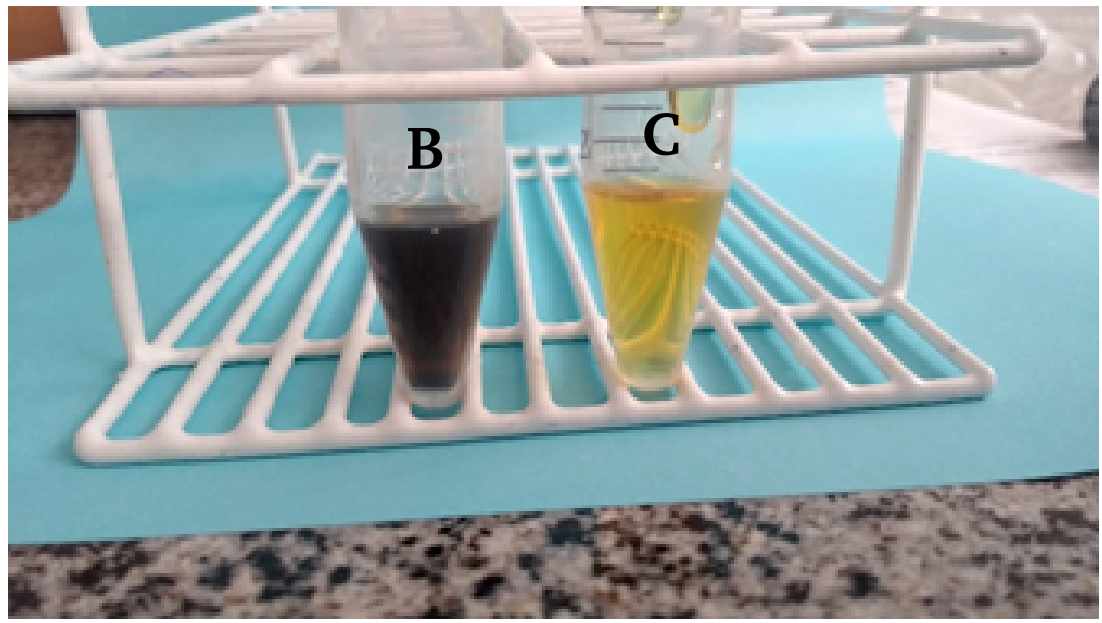

Em que: B: Amostra bovina não hidrolisada; C: Amostra humana hidrolisada

\section{Aprovação do Comitê de Ética}

O projeto foi aprovado pela Comissão de Ética na Utilização dos Animais (CEUA) do Instituto Federal do Norte de Minas Gerais sob o protocolo de número 06/2020.

\section{Referências}

Almeida, P. D. V.; Grégio, A. M. T.; Machado, M. Â. N.; Lima, A. A. S.; Azevedo, L. R. Saliva Composition and Functions: A Comprehensive Review. The Journal of Contemporary Dental Practice, V: 9, N: 3, 1 de março de 2008. Doi: 10.5005 / jcdp-9-3-72.

Alves, K. S.; Carvalho, F. F. R.; Véras, A. S. C.; Ferreira, M. A.; Costa, R. G.; Santos, E. P.; Freitas, C. R. G.; Junior, C. M. S.; Andrade, D. K. B. Níveis de energia em dietas para ovinos Santa Inês: digestibilidade aparente. Revista Brasileira de Zootecnia, v. 32, n. 6, p. 1962-1968, 2003.

Alves, R. S.; Costa, R. H.; Moraes, A. T. B. Screening para verificação de atividade amilásica em saliva de bovinos. 2016. Disponível em: http://conic-semesp.org.br/anais/files/2016/trabalho-1000022101. pdf, Acesso em: 09 de Novembro de 2018.

Andriguetto-Filho, J. M. Sistemas técnicos de pesca no litoral do Paraná: caracterização e tipificação. Raynaut, C.; Zanoni, M.; Lana, P. C.; Floriani, D, p. 213-233, 2002.
Berchielli, T. T.; Pires, A. V.; Oliveira, S. G. Nutrição de Ruminantes. 2. ed. Jaboticabal, SP: Funep, 2011.

Burns, L. V.; Helayel, M. A.; Silva, M. A. G.; Maruo, V. M.; Córdova, F. M.; Silva, S. L.; Barros, C. S. L.; Ramos, A. T.. Doenças de animais de produção na região centro-norte do Estado de Tocantins: 85 casos. Arq. Pesq. Anim, v. 2, n. 1, p. 1-6, 2013.

Caraway, W. T. A stable starch substrate for the determination of amylase in serum and other body fluids. American Journal of Clinical Pathology, v:32, p. 97-99, 1959. Doi: https://doi.org/10.1093/ajcp/32.1_ts.97.

Gheller, L. F. M.; Bueno, A. V. I.; Kastelijn, D.; Carneiro, M. K.; Marcantonio, M. Perfil da população de grandes animais assistidas pela clínica escola veterinária (Cevet, Unicentro) no biênio 2008-2009 em relação às principais espécies atendidas e os sistemas acometidos. Anais XIX Encontro Anual de Iniciação Cientifica (EAIC), Universidade Estadual do Centro-Oeste, Guarapuava, PR. 4p, 2010. 
Análise da presença da atividade da enzima alfa-amilase salivar na espécie bovina

Hall, J. E. Guyton \& Hall. Tratado de fisiologia médica. Elsevier Health Sciences, 2011.

Klein, B. G. Cunningham tratado de fisiologia veterinária. 5. ed. Rio de Janeiro: Elsevier, 2014.

Lima, A. G.; Arêas, V. S.; Júnior, L. V.; Silva, P. C. A. R.; Nunes, L. C. Atendimento na rotina da clínica médica de animais de produção do hospital veterinário, UFES, entre os anos de 2004 a 2008. IXI Encontro Anual de Iniciação Científica (EAIC), Universidade Estadual do CentroOeste, Guarapuava, PR, 2008.
Lima, R. N.; Moura, A. K. B.; Miranda, M. V. F. G.; Lima, P. O.; Morais, J. H. G.; Lopes, K. T. L. Limitações da fisiologia dos animais em transição. PUBVET, v. 7, p. 170-258, 2013. Doi: 10.22256 / pubvet.v7n3.1496.

Reece, W. O. Dukes: fisiologia dos animais domésticos. 13. ed. Rio de Janeiro: Guanabara Koogan, 2017.

Young, J. A.; Schneyer, Charlotte A. Composition of saliva in mammalia. Australian Journal of Experimental Biology and Medical Science, v. 59, n. 1, p. 1-53, 1981. Doi: https://doi.org/10.1038/icb.1981.1. 